\title{
sciendo
}

\author{
Current Issues in Pharmacy and Medical Sciences \\ Formerly ANNALES UNIVERSITATIS MARIAE CURIE-SKLODOWSKA, SECTIO DDD, PHARMACIA \\ journal homepage: http://www.curipms.umlub.pl/
}

\section{Asymptomatic traumatic neuroma}

\author{
Katarzyna Wrona ${ }^{1}$, Agnieszka Mocarska ${ }^{2}$, Wojciech Wrona ${ }^{3}$ (D), \\ Luiza Grzycka-KowalczyK ${ }^{4}$, Maciej Burdan ${ }^{1}$, Artur FaleK ${ }^{1}$, \\ Adrian KARBOWNIK ${ }^{2}$, FranCISZEK BURdAN ${ }^{1,2 *}$ (D)
}

\author{
${ }^{1}$ Department of Human Anatomy, Medical University of Lublin, Jaczewskiego 4, Lublin, Poland \\ ${ }^{2}$ Department of Radiology, St. John's Cancer Center, Jaczewskiego 7, Lublin, Poland \\ ${ }^{3} 3^{\text {rd }}$ Department of Gynecology, Medical University of Lublin, Jaczewskiego 8, Lublin, Poland \\ ${ }_{4}^{4} 3^{\text {rd }}$ Department of Radiology and Nuclear Medicine, Medical University of Lublin, Jaczewskiego 8, Lublin, Poland
}

\begin{tabular}{|c|c|}
\hline ARTICLE INFO & ABSTRACT \\
\hline $\begin{array}{l}\text { Received } 12 \text { August } 2018 \\
\text { Accepted } 24 \text { September } 2018\end{array}$ & \multirow{2}{*}{$\begin{array}{l}\text { A rare case of asymptomatic traumatic neuroma, triggered by the performed amputation } \\
\text { within the right thigh due to the osteosarcoma is reported. The MRI examination has } \\
\text { shown a focal lesion at the end of the sciatic nerve, with isointense signal and weak } \\
\text { contrast enhancement on T1-, high signal on T2-weighted images, without restriction } \\
\text { diffusion on DWI. The morphology did not significantly change after } 12 \text { months, which } \\
\text { confirms the primary diagnosis. The main limitation of the case is the lack of histological } \\
\text { confirmation, since the lesion was not removed. }\end{array}$} \\
\hline $\begin{array}{l}\text { Keywords: } \\
\text { traumatic neuroma, } \\
\text { sciatic nerve, } \\
\text { incidental findings. }\end{array}$ & \\
\hline
\end{tabular}

\section{INTRODUCTION}

Traumatic neuroma (stump or amputation neuroma) is a painful phenomenon that results from an acute or chronic injury, and may complicate various surgical procedures. The lesion is found at the end of an injured nerve as a presentation of ineffective, unregulated nerve regeneration. It occurs most commonly near a scar, either in a superficial or deep manner [1], and may develop 1-12 months after the damaging of the nerve [2]. The patient usually reports a focal pain and a tenderness to palpation. The treatment and prevention strategies arer be more successful if targeted at the initial stages of development [3].

\section{CASE REPORT}

A 31-year-old female underwent magnetic resonance, as a routine follow-up procedure 12 years after right leg and distal thigh amputation due to the osteosarcoma of the femour. The diagnostic procedure was performed on 1.5T scanner with fast spin echo T1- and T2-weighted images with and without fat saturation, as well as after intravenous injection of the macrocyclical gadolinium-based contrast (gadobutrol). Diffusion weighted images was obtained using $\mathrm{b}$ values of $0,50,100,500$ and $1000 \mathrm{~s} / \mathrm{mm}^{2}$, and an ADC (apparent diffusion coefficient) map was automatically generated. The initial post-operative examination showed a well-demarcated, partially capsulated lesion $(19 \times 26 \mathrm{~mm})$ at the end of the sciatic nerve, in the posterior compartment of the thigh on the level of the upper apex of the popliteal fossa. It generated an intermediate signal on T1-weighted images, isointense to the surrounding muscle. The lesion was hyperintense compared to muscle tissue and the proximal part of the nerve on T2-weighted images, especially after fat saturation. A clustered hypointense ring-like areas (fascicular sign) on T2-weighted, very weak contrast enhancement, as well as lack of restriction diffusion (ADC vale of $1,293 \times 10 \mathrm{~mm}^{2} / \mathrm{s}$ ) were observed. Based on the morphology and the previous surgery, a primary diagnosis of traumatic neuroma was suggested. The size change slightly after 12 months $(15 \times 29 \mathrm{~mm})$, while the signal characteristic was the same when compared with an initial examination. However, it has to be stressed that the patient underwent 8 courses of AP3 (doxorubicin and cisplatin) and 6 courses of IFO7 chemotherapy (ifosfamide) after 3 years from the first therapy due to local recurrence. The treatment of traumatic neuroma was not suggested due to lack of any serious clinical symptoms.

\section{DISCUSSION}

The removal of extremities due to a trauma, as well as various vascular or oncological lesions is often necessary. Sometimes it is the only possible treatment that can bring about a cure for the encountered disorder and prolong life. 

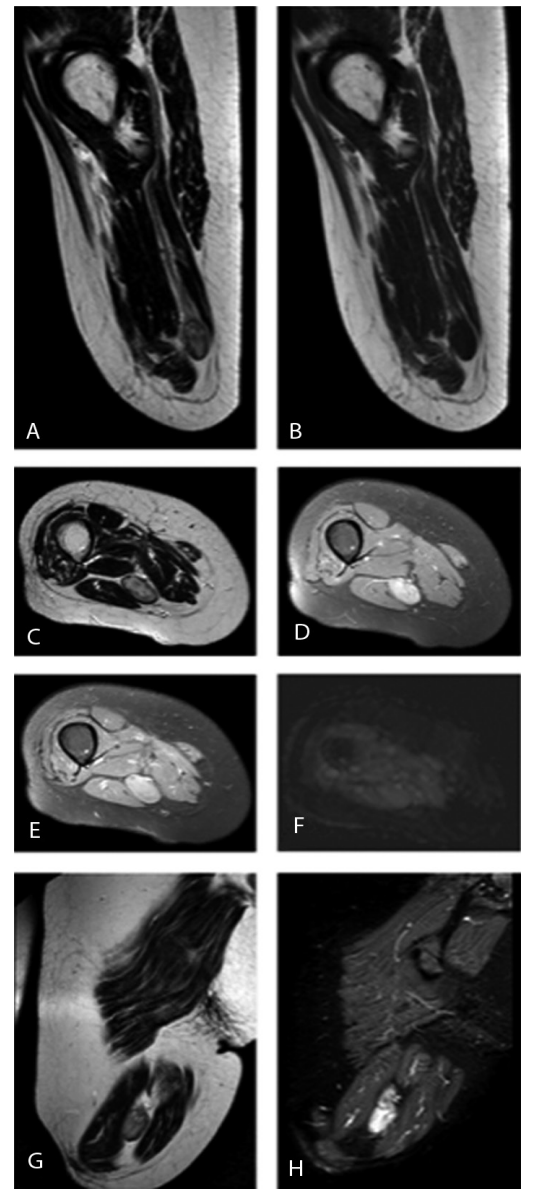

Sagittal T2- (A) and T1-weighted image (B). Axial T2- (C), T1-weighted image with fat saturation without (D) and after contrast enhancement (E). ADC map (F). Coronal T2-weighted image without $(\mathrm{G})$ and after fat saturation $(\mathrm{H})$

Figure 1. Traumatic neuroma of the right sciatic nerve

Stump pain is a common complication of such procedure, and traumatic neuromas account for $10-25 \%$ of chronic post-amputation pain. Until now, 251 cases of traumatic neuroma have been described in the PubMed database. They can occur in any location, not only in the limbs, but also in the visceral and cranial nerves [4]. From a radiological point of view, the differential diagnosis of the lesion includes Morton neuroma (no history of prior trauma or surgery and the involved nerve stays intact), mucosal neuromatosis (but they a usually multiple), solitary circumscribed neuroma (mostly affect the face and are usually located in dermis and there is no history of prior trauma or surgery), as well as neurofibroma and schwannoma (neither trauma, nor surgery are present) [2,5]. The main limitation of the reported case is the lack of histological confirmation, since the patient was not re-operated.

Unlike in the presented case, as the condition is usually very painful, it is very important to treat the patient in the most effective way. The available methods include conservative treatment (opioids and non-opioid analgesic, antidepressants, anticonvulsants), minimally invasive procedure (cryoablation or direct injection of corticosteroid, ethanol, phenol) as well as the total excision. Various alternative methods such as acupuncture, physical therapy, neuromodulation has also been suggested [1-4].

\section{ORCID iDs}

Wojciech Wrona Dhttps://orcid.org/0000-0002-9023-4462 Franciszek Burdan Dhttps://orcid.org/0000-0001-5305-8829

\section{REFERENCES}

1. Woertler K. Tumors and tumor-like lesions of peripheral nerves. Semin Musculoskelet Radiol. 2010;14:547-58. doi: 10.1055/s-0030$-1268073$.

2. Ahlawat S, Belzberg AJ, Montgomery EA, Fayad LM. MRI features of peripheral traumatic neuromas. Eur Radiol. 2016;26:1204-12. doi: 10.1007/s00330-015-3907-9.

3. Oliveira KMC, Pindur L, Han Z, Bhavsar MB, Barker JH, Leppik L. Time course of traumatic neuroma development. PLoS One. 2018;13:e200548. doi: 10.1371/journal.pone.0200548.

4. Terzi A, Kirnap M, Sercan C, Ozdemir G, Ozdemir BH, Haberal M. Traumatic neuroma causing biliary stricture after orthotopic liver transplant, treated with hepaticojejunostomy: a case report. Exp Clin Transplant. 2017;15(Suppl 1):175-177. doi: https://doi.org/10.6002/ ect.mesot2016.P52.

5. Abreu E, Aubert S, Wavreille G, Gheno R, Canella C, Cotten A. Peripheral tumor and tumor-like neurogenic lesions. Eur J Radiol. 2013;82(1):38-50. doi: 10.1016/j.ejrad.2011.04.036. 